\title{
Live surgery should not be outlawed at national and regional cardiothoracic meetings
}

\author{
Hugo K. Vanermen, MD
}

I would like to shed more light on the usefulness, ethical aspects, and excesses of live surgery. My first question is: What is live surgery? Is it a platform for education?

"When it comes to education, there is little doubt that the future of our marvelous profession is in the residents whom we educate.' I cherish this statement from the Association's president-elect, Irving Kron.

Observation is crucial in surgical education. That is the way training has been done for decades. Ideally, training is carried out bedside or next to the operative table. There was no other technology available for ages. It is live surgery on a daily basis. An experienced surgeon explains to 1 or 2 young apprentices his/her observations, his/her diagnoses and thought processes, and the best surgical treatment for the patient.

This ideal situation is impossible in peculiar circumstances. Vision is mandatory for good observation, and it is easy when 1 surgeon teaches 2 young residents. Visualization may become difficult when there are exceptional things to see: There are too many interested eyes and the theater fills up with residents, standing unstably on all sorts of steps and jeopardizing the sterility and mindfulness of the surgeon, which is distinctly at odds with the patient safety initiative and "far from the chapel or solemn-looking environment that is needed for accurate work."

Vision is impossible when the access is very small, as in modern mini-access surgery, and it is difficult to have someone see what you are doing, let alone teach him/her how to do it.

In both instances, the technology of the 21 st century can obviously help. When the endoscope is in the thorax or the cavities of the heart, it is easier for a surgeon to see inside and gives residents, anesthesiologists, perfusionists, and scrub nurses the opportunity to follow what is going on. When there are cameras all around the theater, the ideal setup for surgical education is a viewing room where people can sit down without bothering medical practitioners and look at monitors to view fluoroscopic images, electrocardiograms, echocardiograms, and the action around the table and inside the thorax or heart.

From the Department of Cardiovascular and Thoracic Surgery, Onze-Lieve-Vrouw Clinic, Aalst, Belgium

Received for publication June 20, 2008; accepted for publication Dec 18, 2009.

Reprint requests: Hugo K. Vanermen, MD, 9300 Aalst, Belgium (E-mail: hugo. vanermen@olvz-aalst.be).

J Thorac Cardiovasc Surg 2010;139:822-5

$0022-5223 / \$ 36.00$

Copyright (c) 2010 by The American Association for Thoracic Surgery doi:10.1016/j.jtcvs.2009.12.032
So let us have all those who jeopardize the sterility and concentration of the surgeon move out and have a comfortable seat in the viewing room where they can observe and learn, and share the experience of the surgeon. This is what modern teaching is all about. From this viewing room, there can be audio contact with the surgeon to ask questions, although this is not yet filtered by a moderator, an element that is added by true modern live surgery.

My thesis is that there is little or no difference between the situation where 1 surgeon teaches 1 or 2 residents while they are peering over his/her shoulder and the live surgery situation with an audience of multiple colleagues observing surgery as soon as some rules of conduct or guidelines are respected. On the contrary, there are multiple advantages.

The latter situation is probably preferable for the surgeon, because there is nothing more bothersome than an unannounced visitor with unfiltered questions on a Monday morning. I have visitors from all over the world every day for a simple reason. They want to be familiar with tomorrow's techniques and be ready for the real world. This is the advantage in well-organized live surgery: A good moderator can filter irrelevant questions and guide observers to the more important steps of a procedure that are often overseen by young residents and visitors. A moderator can undoubtedly help surgeons in their teaching job. In addition, attendants can follow the thought processes of surgeons, which is impossible in edited tapes. That is why they remain in their chairs for hours during live surgery: to experience the real world, not the drama or sensation. The statement that "modern live surgery has no educational value" does not make sense; peering over a surgeon's shoulder during surgery is the worst possible scenario. A surgeon who has developed particular skills in a subspecialty and as a result has more experience because of the workload does not have the right to close his/her doors to colleagues who are eager to learn in the true sense of the word and to try to reproduce the surgeon's skills.

Live surgery is the key success factor of the Master of Valve Repair, where learning, sharing and finally mastering is the purpose. This program was initiated 7 years ago as an educational tool to enhance the practice of mitral valve surgery, and it has done so. In responsibly organized live surgery, as in the Master of Valve Repair, rules of conducts are wholly important, that is, selection of the right moderators, surgeons, and patients.

Why select the right moderators? They have to avoid frequently asked irrelevant questions and raise the occasionally unasked interesting question. Comments and questions that 
may give way to highly debatable issues during surgery have to be avoided. The moderator has the task of feeling the tension in the operative suite, minimizing the distraction, and recognizing the subtle moments of the surgery to avoid any interference with the treatment of the patient and possibly interrupt the teleconference to quietly handle arising complications.

Selection of the right surgeons is important! They have to be immune to the conditions of live surgery, they should never be swept by the fever of the live setting like a pilot in an air show, and they should be very interested in teaching. Some are capable of handling these particular circumstances, and others are not.

Finally, what is it like for the correctly chosen patients? Sometimes it is the opportunity to undergo operation by the most experienced surgeons in the subspecialty. The repair ratio was more than $98 \%$ in difficult pathologies such as rheumatic disease, Barlow's disease, and other diffuse calcifications. This can hardly be said of daily practice in some countries where repair ratios are less than $45 \%$. In a few cases, the decision to commute the planned repair into a mitral valve replacement was taken on-line as in real life.

All these courses had a limited attendance of approximately 80 participants to remain a smaller workshop and stimulate interaction among surgeons, moderators, and participants. Live surgery is the key success factor of the Master of Valve Repair and the most popular aspect of the course. Attendees frequently mention in their evaluations that live surgery is the most interesting and informative part of the event. The "live" operation always receives high ratings.

All course directors of the Master of Valve Repair, officially supported by the EACTS, are responsible for the surgery to bring honesty by exposing all attendants to each step but never to bring spice and drama or, under no circumstances, to be at odds with the patient safety initiative. Does live surgery as an educational tool carry more risk? If one looks at the results of "the Masters" of the last 7 years, we can only assess that 155 patients have undergone operations with a 30-day hospital mortality that was virtually nil and a repair ratio of more than $98 \%$.

A frequent argument against live surgery is that edited videotapes would be as good for educational purposes and less risky to the patient. I do not agree. What we like to share with young people is fine observation of the real world that the experienced surgeon can unveil as a good guide. Do you want guides to shed a light on a fake world?

It is of no interest to shed light on a fake world, and I am convinced that live surgery is the real world, whereas videotapes are a fake world. That is exactly why these tapes are boring and why nobody stays in his/her chair to view the tapes for 4 or more hours. The creators of edited tapes usually do not hide their intentions of idealizing the world.

How about the teaching value? Videotapes look like the finished work of a composer or painter. If you want to know how artists proceed and what their thought processes are during the realization of the job, then move into their workshops and see them at work. That is where one can learn and witness the true process of the work of art, which all surgical procedure should be. Surgery during videotapes is $\mathrm{em}$ bellished; videotapes invariably start with a bird's-eye view of the hospital and finish with the patient strolling along the beach. The images of the procedure that are not that nice are omitted. Thus, edited videotapes are an illusion. Videotapes look treacherously simple just because they are edited. They always show a nice sequence of actions: The hiccups are left out. They create an illusion.

Live surgery at national and regional cardiothoracic meetings should definitively not be outlawed: no ban as a forum for education. There is an educational significance to live surgery because it conveys the realities and tensions of the practice of surgery while bringing to light the performance of highly practiced surgeons in real time in a manner relevant to the age of information technology.

\section{PLATFORM FOR NEW TECHNOLOGY}

"There is little doubt too that the future of our marvelous profession is in innovation." -Robert Guyton, past president of the Society of Thoracic Surgeons.

Live surgery as a platform for new technology is more debatable. We still enter a real world, but it may be tempting to sell prime time to the industry and for participants just to come and wait for a crash. However, it is still the best platform to show new technology because it is the real world, and that is why, in Leipzig, a biannual congress has been organized to pioneer the latest techniques. Many live surgeries have been performed in Leipzig during the past few years. It is why I created Techno-College in 1998 and brought it under the auspices of the EACTS.

On November 28, 2005, Bruce Keogh, the former secretary general of EACTS, noted that the Council of EACTS assessed that Techno-College had become established as the most popular part of the EACTS annual meeting and had contributed enormously to the educational and financial success of the meeting. In 2009, there were more then 1200 registries. This is undoubtedly because of its basic ingredients. In times when the profession of cardiothoracic surgery is at stake, Techno-College gives a glimpse of what new technology can offer in terms of new products for the visionary cardiothoracic surgeon, at least when it is wisely implemented in novel techniques that offer patient benefit at no additional price.

There is more. Techno-College does this in a package that is exciting and keeps attendants on their chairs for hours, namely, by surgery demonstrated live. There is no doubt that Techno-College is a beautiful platform for the industry and is part of its success too.

The annual meeting of EACTS would never be the same conference without the aspect of the glimpse at the future, even when these procedures do not have the scientific value 
of long-term follow-ups. That is how the EACTS annual meeting has become a marvelously balanced conference, featuring scientific sessions, postgraduate courses, and Techno-College, and it has proven to be increasingly successful. Techno-College will be able to continue to exhibit live surgery in the future. Its life may depend on it!

The most common request from delegates at Techno-College has invariably been to increase the time spent on live cases and to strictly adhere to live program timing so the real obstacles of the procedure can be repeatedly observed.

Does it carry more risk to perform live surgery on a patient with new technology, for example, during the pioneering techniques that have been organized in Leipzig for 5 years? A wide variety of surgeries in 77 patients have been carried out without 30-day or hospital mortality. My personal experience in live surgery is 81 live cases all over the world, with no mortality and a $100 \%$ repair rate in 55 mitral valves. Thus, as a platform for new technology, live surgery should not be banned because it is the only thing that can really tell us whether new technology is going to work in real life.

Videotapes of the industry of new technology look like commercials. Live surgery sessions have been an eyeopener for attendants on many occasions. One image can be worth a thousand words. There used to be a promising technology for distal anastomoses during coronary artery bypass surgery that was based on magnet attraction. The technology was praised as the future for coronary artery bypass grafting but never came to widespread use. In a live session it invariably looked like a quirky act. There was another one on proximal anastomosis. There have been many live procedures where people could assess for themselves that it was a nerve-wracking moment to release the device, certainly on a bad ascending aorta, with disconnections as a result. Moreover, there has never been any live session on computer motion robot technology. This was announced as an extremely promising technology in press announcements and videotapes, but everyone who has worked with it in real life knows it was just blood, sweat, and tears and that creating an anastomosis took forever. Live surgery to present new technology should not be banned but subject to vigilant supervision by a particular committee to respect the proper guidelines.

\section{CIRCUS FOR SHOWMEN}

Live surgery should never become a circus for showmen with the intention to promote the institution or the ego: We should stay away from this at all times!

"Sensationalism is incompatible with professionalism," of course, but there are also many examples of sensationalists in daily surgery without cameras.

My basic thoughts on the subject are as follows: Banning means asking for illegal practice; not banning means regulation. Have everybody respect the rules of conduct.
One more note on live surgery: Do I have to allude to the long-term activities of masters, such as Alain Carpentier, Magdi Yacoub, and Tirone David? Without their continuous efforts and numerous live teaching courses, the techniques of mitral valve repair, aortic valve repair, and the Ross procedure would not have received widespread worldwide acceptance and technical perfection.

In addition, there are the EACTS live courses directed by Marco Turina in Eastern Europe, which are considered to be a mission of EACTS, using expert surgeons from around the world to teach the best and most modern practice.

\section{SUMMARY OF COMMENTS ON THE GUIDELINES}

It is unethical to have a patient sign an informed consent form stating that live surgery carries more risk. Nobody has ever considered signing an informed consent for patient-side teaching in crowded theaters, which carries more risk. Informed consent can arguably be asked in all cases of endoscopic surgery, which is carried out in some centers on a daily basis and visitors also ask questions during surgery. They look at the same image as the surgeon because there is a camera inside the patient's heart, belly, or knee. Furthermore, it is irrelevant whether the audience consists of 5 or 50 people. Common sense dictates the need for oral informed consent before live broadcasting.

Expected and unexpected complications are part of the real world, as well as for the "expected and unexpected" observer in the theater. During live surgery, it is the moderator's task to protect the patient's privacy and other concerns on the intimate aspect of a particular event, such as a cardiothoracic intervention. Broadcasting should be stopped in some circumstances just as observers should be sent away from the theater.

It is easier to spread edited surgical videotapes on the net to a nonclinical audience than live images, if it were for the sake of sensation! Video recordings do sometimes, in the quest for superior images, interfere more with the surgical activities in progress than live sessions. I have never been to a conference where prerecorded "live" tapes were viewed and commented on for hours without any editing.

I do agree that live surgery should be staged from centers where the surgical teams, from anesthesiologists, surgeons, nurses, to perfusionists, have proven to have sufficient experience with live surgery to avoid any interference with a patient's treatment.

Patient selection should be restricted to those with ailments frequently encountered in medical practice and those requiring general surgical procedures. However, even among those requiring general surgical treatment, patients with ailments that have high mortality rates should be avoided for obvious reasons of respect.

In the relevant department, a conference attended by the surgeon should be held beforehand, and confirmation of matters related to the safety standards, ethical principles, 
and qualifications of surgeons and moderators should be made. The content of the conference must be disclosed beforehand to those intending to watch the session of live surgery.

The new equipment and devices used in live surgery must be strictly limited to those deemed essential from the viewpoint of scientific significance, and any use for solely commercial purposes must be avoided, even if no monetary exchange is involved.

The lawyers' views on the subject are "commonsense" matters; live performance should under no circumstances be an additional risk for the patient. Whether it will be a factor that might encourage patients to confront surgeons with court rooms is regrettable and may not be avoided. It is actually the only downside but is so far unseen in Europe.
"Live in a box" is the solution for the United States. Live commentary instead of a voice-over, together with very limited editing, guarantees the lively aspect.

\section{CONCLUSIONS}

Modern information technology is there to overcome the practical problems related to teaching through observation. Let us use it responsibly. It would be unwise to handicap education and innovation by banning live surgery. A committee should regularly revise appropriate guidelines and properly watch the implementation of the rules of conduct in all forms of live displays. It goes without saying that personal or institutional promotion can never be the purpose of live surgery. 